\title{
The history of the Méchanique analitique
}

\author{
Sandro Caparrini
}

Published online: 6 June 2014

(C) Centro P.RI.ST.EM, Università Commerciale Luigi Bocconi 2014

\begin{abstract}
A description of the historical development of the ideas that led Lagrange to write his Méchanique analitique (1788).
\end{abstract}

Keywords Lagrange - Méchanique analytique .

Analytical mechanics · History of mechanics - History of physics $\cdot 18$ th-century mathematics

\section{Mechanics after Newton}

Few read the classics of literature, very few the classics of science, and only a tiny minority go beyond the first pages of the classics of mathematics. In an ideal classification of books that are often cited but little read, Lagrange's Méchanique analitique [16] would occupy one of the first places. The footnotes in books of advanced mechanics limit themselves to saying that it gave the origin to this discipline, called in fact "analytical mechanics". General histories of science explain that it represented the culmination of the mechanics of the 1700s, but rarely go beyond.

To comprehend the role of the Méchanique analitique in the history of science, we must go back to the publication of Newton's Principia in 1687. An old historiographical tradition would have us believe that Newton discovered a large part of classical mechanics, leaving to his successors the simple task of developing the formal aspects. In reality, things were different. In the Principia are found solved with semi-geometrical methods many important problems

S. Caparrini $(\bowtie)$

Dipartimento di Matematica, Università di Torino, Via Carlo

Alberto 10, 10123 Turin, Italy

e-mail: sandro.caparrini@unito.it on the motion of a point subject to the action of a central force, but there is nothing that comes close to a constrained system. Fluid mechanics is set out there in a primitive form, the rigid bodies are almost completely lacking, and vibrating systems are barely mentioned. To develop these theories, a new mathematics was necessary, but above all there was a need for new physical principles.

In the decades following the publication of the Principia, the gigantic problem of the creation of a mechanics of systems in analytical form was addressed by three generation of first-rate mathematical physicists $[2,5,6,8$, $13,22,23,26,28]$.

The first generation was formed of Newton's contemporaries. Between 1690 and 1710, Pierre Varignon and Johann Bernoulli translated into Leibnizian notation many of the results of the Principia. Jacob Hermann, in the Phoronomia of 1716, expressed Newton's second law by means of the formula $f=m d v / d t$. Johann Bernoulli's solution of the catenary problem in 1691 and the analysis of his brother Jacob of the elastic deformation of a beam fixed in a wall in 1694 gave rise to continuum mechanics.

The second generation arrived on the scene shortly before 1730. Its principal members were Daniel Bernoulli, Leonhard Euler, Alexis Clairaut and Jean le Rond d'Alembert. What they had in common was that they were all born at the beginning of the century, they had all mastered the subtleties of Leibnizian calculus in their adolescence, and they had all absorbed the Principia before the age of eighteen. Directly or indirectly, they were all students of Johann Bernoulli. Their discoveries were so many and so significant that even a simple list would require too much space. Here we will limit ourselves to recalling that they left as a legacy rigid body dynamics, the theory of perfect fluids and several fundamental chapters on linear elasticity. To them we owe the theorems of conservation, the concept 
of potential, the principles of statics and dynamics for systems, and the perturbation theory in astronomy.

Around 1760, mechanics began to resemble what is taught today in our universities. In order to see this, we need only place a memoir by Euler and a chapter of the Principia side by side. A capable graduate in physics or mathematics of our own day might be able with some effort to understand Euler (providing that he or she can read Latin), but only an expert is able to appreciate Newton. In any case, in spite of the enormous progress, the mechanics of that period still presented itself as a collection of separate theories. There existed neither a general formulation nor a well-defined connection between the various principles. It was at this point that the leading figure of the third generation of Newton's successors came on the scene: Lagrange. He was some 30 years younger than Euler and d'Alembert. At the age in which today's youngsters finish middle school, within a couple of years he had completely mastered all of the mathematics and mechanics produced in the preceding decades. He had an in-depth knowledge of the very recent theory of partial differential equations, the key to accessing continuum mechanics. Fortified with these weapons, Lagrange very early on set for himself the objective of unifying all of the mechanics known in his day.

\section{The Lagrangian program for formalizing mechanics}

When he published the Méchanique analitique, Lagrange was 52 years old. Not all in the book was new: many of the results had appeared previously in his own works and those of Euler. It would be a mistake, however, to believe that this was merely the attempt of a mathematician on the road to senility to coordinate his own youthful discoveries. To the contrary, first there was born a project for a text that would unify all of mechanics, and only after there came the single results. The dream of a unification and formalization of mechanics is the pillar that supported all of Lagrange's research in mathematical physics.

Lagrange had already mentioned his studies on the foundations of mechanic in his first letter to Euler, ${ }^{1}$ written on 4 July 1754 when he was only 18 years old. Included in a list of the results that he wished to discuss in the future were "some observations on the maxima and minima that are found in the actions of nature". This was a reference to the principle of least action, formulated by Pierre-Louis de Maupertuis and by Euler in 1744. In Maupertuis's version, the principle of least action stated that the motion of a system of bodies subject to the action of any given forces

\footnotetext{
1 The correspondence of Lagrange is found in [17, vols. XIII and $\mathrm{XIV]}$ and [13].
}

was such to minimize the product of the velocity times the distance traveled. The idea was promising but the formulation was obscure, and the exposition reduced itself to a display of rhetoric. Euler addressed the problem, with a completely different style, in the appendix to his book on variational problems, the Methodus inveniendi [9]. Applying the purely mathematical results of the first part, Euler proved that in the case of a single material point subject to the action of centralized forces, the integral.

$\int_{P}^{Q} v d s$,

(where $P$ is the point of departure, $Q$ the point of arrival, $s$ the length of the arc of the trajectory) turns out to be minimum in correspondence to the effective trajectory. This is a noteworthy result but certainly not sufficient as a basis for dynamics, as Maupertuis had claimed. In 1748 Euler expressed the opinion that there was still a long way to go (encore bien éloignés) to finding the magnitude to be minimized for any given mechanical system.

The problem that Euler considered the most difficult was solved by Lagrange almost as a consequence of his discovery of the calculus of variations. Let us recall that Lagrange intuited the calculus of variations in 1755 after having read the Methodus inveniendi. A first draft of the new algorithm appeared in his second letter to Euler, 12 August 1755; Euler replied immediately, on 6 September 1755, with compliments on this important discovery. The discussion then shifted to mechanics. The next letter of Lagrange, dated 20 November 1755, contained an analytical solution of the problem of finding the curve of the quickest descent of a material point along a vertical plane from a fixed point to a given curve.

At the beginning of 1756, Lagrange sent Euler a memoir on the principle of least action for publication in the proceedings of the Berlin Academy of Sciences. At that time, he already thought that the principle "should be considered as the key to all problems, both static and dynamic", as stated in a letter to Euler of 19 May 1756. Thus, at a distance of only a year from the discovery of the calculus of variations, Lagrange aimed at deducing the whole of mechanics from the principle of least action.

In effect, we get the impression that, from the end of 1755 until about 1760, Lagrange devoted himself above all to mechanics. His memoirs of that period regard the principle of least action, the propagation of waves, the vibrating strings, and the solution of the partial differential equations of fluid motion. Besides the purely scientific satisfaction of solving the most important problems in mathematical physics of the day, what was at stake was the possibility of obtaining the academic support of Euler and Maupertuis. 
After having sent to Berlin the memoir on least action, Lagrange set to work to prepare a complete treatment of his own variational results. On 4 May 1757 he wrote to the Milanese mathematician Paolo Frisi to say that he had almost finished two dissertations: the first regarded the calculus of variations; the second consisted:

...nell'applicazione del Principio Maupertuisiano a tutti i casi più complicati della Dinamica ed Idrodinamica, ricavando da esso delle formole generalissime per cui, dato un sistema qualunque di corpi, colle leggi delle forze sollecitanti si vengono a dirittura e con facilità grandissima a ritrovare tutte le equazioni necessarie per la determinazione del moto di ciascun corpo.

(...the application of the Maupertuisian principle to all the most complicated cases of dynamics and hydrodynamics, deriving from them the most generalized formulas by which, given any system whatsoever of bodies, with the laws of the soliciting forces one arrives directly and with the greatest ease at finding all of the equations necessary for the determination of the motion of each body).

With the passing of time, the mass of results grew. In 1759, the two dissertations had taken the form of a book centered above all on mechanics. Lagrange spoke of it in a letter to Daniel Bernoulli dated 15 November 1759:

Since I am working on a work [un Ouvrage] whose aim is to deduce in a simple and general way the solution of the most complicated problems, both of equilibrium and of motion, from the sole formula of the least quantity of action, I am quite desirous of knowing what you have discovered regarding the elastic curves by means of this formula.

We can consider this treatise as the first step towards the Méchanique analitique.

While he was involved at the same time in the creation of a new branch of analysis and in the refounding of dynamics, Lagrange also had to draft two series of notes (on analysis and mechanics) for the students at the Royal School of Artillery in Turin [3]. Of the notes on analysis a single copy has survived; instead, those on mechanics have been lost since the beginning of the 1800s. To be sure, these elementary notes for students were too far from the advanced methods of higher mechanics to constitute a first version of the extremely difficult Méchanique analitique. However, Lagrange maintained that he had organized the text according to la vraye metaphisique (the true metaphysics) of mechanics. In the terminology of the $1700 \mathrm{~s}$, the "metaphysics" of a science was its methodological foundation. We can thus hypothesize that the notes on mechanics for the young Turinese artillerymen carried some weight in the evolution of this thinking on the principles of mechanics.

In 1756 the correspondence between Euler and Lagrange was interrupted due to the seven Years' War. It began again in 1759, when Lagrange was able to have delivered in Berlin two letters (28 July and 4 August 1759) and the first volume of the Miscellanea philosophicomathematica of the Turinese Private Society (the future Academy of Sciences). Among other things, he asked Euler if it would be possible for him to print his book in Berlin.

Let us summarize the situation as it presented itself by mid-1759. For about three years Lagrange had written about and reflected on the calculus of variations and on the unification of dynamics; however, he had not yet published anything, and only a very few knew of his research. He was awaiting the publication of a memoir on the principle of least action in the proceedings of the Berlin Academy, and kept on his desk a complete treatise, by then ready for publication. In the meantime, on the sole basis of his results sent by letter to Euler and Maupertuis, he had been elected a corresponding member of the Academy of Sciences of Berlin.

This humming and hawing with publications finally ended as would have been logical to expect it to. On 2 October 1759 Euler replied to Lagrange. He thanked him for the gift of the Miscellanea, advised him to publish the book on least action in either Geneva or Lausanne, and told him about the death of Maupertuis. Further, almost as an aside, he let him know that he had presented to the Berlin Academy, 3 years earlier, two papers on the new calculus of variations. For the sake of propriety, he had asked that the papers not be published until Lagrange had made the results of his own research known. No mention was made of the memoir on the principle of least action, sent in 1756 (of which no trace remains today).

It is difficult at a distance of two centuries and a half to interpret the feelings of a man as reserved as Lagrange, but there are enough clues to allow us to believe that he felt betrayed. His resentment can be intuited by reading the sarcastic remarks on Euler that occur in his correspondence with d'Alembert. Euler, for his part, appears not to have been too interested in the successes of the principle of least action. Perhaps the Lagrangian vision of mathematical physics was too formal for his tastes.

At this point it was necessary to publish without further delay. The following year Lagrange inserted two memoirs, one on the calculus of variations, and the other on the principle of least action, in the second volume of the Taurinensia Miscellanea. Here the treatment is extremely bare-bones and concise; it is probable that these are summaries of the memoirs that about which he had written to Frisi in 1757. In the letter of 28 October 1762 that accompanied the gift of the volume to Euler, Lagrange 
explained that he had believed that "he had to suppress that which he had almost obtained on the topic", rendering the exposition "as short as possible" after having learned of the imminent appearance of Euler's works on the calculus of variations. The choice to publish two truncated papers rather than the complete development of fundamental discoveries reveals something of his closed, proud nature. Surprisingly, he thanked Euler for having reformulated in his own way the calculus of variations: "I am impatient to be able to profit from the new light that you have shed on such a difficult subject; in the meantime I beg you to received my most humble thanks for the honor that you have wished to do me, and that I consider as the most flattering compensation for my mathematical studies". This is the first example of the subtle and ferocious irony that Lagrange could evidence.

The second memoir, entitled "Application de la méthode exposée dans le Mémoire précédent à la solution de différents problèmes de dynamique" [15], is in effect a small treatise on the principle of least action generalized to systems of constrained points. Lagrange defines the quantity to be minimized as the sum over all points of Euler integrals, each multiplied by its mass:

$m_{1} \int_{P}^{Q} v_{1} d s_{1}+m_{2} \int_{P}^{Q} v_{2} d s_{2}+\cdots$ etc.

(where $m_{1}, m_{2}, \ldots$ etc. are the masses) with the condition that the conservation of energy holds. Thus the relationship that Euler held to be almost impossible to discover was none other than an immediate extension of the formulas given in the Methodus inveniendi. Why was Euler not the first to arrive at it? The explanation lies in the different scientific concepts of the two mathematicians. Simplifying the question somewhat: for Euler it was necessary to prove on the basis of the laws of mechanics that a certain integral had to be rendered minimum, while for Lagrange it was sufficient to find an expression that led to correct results. From that time, the two methods continued to recur in the history of theoretical physics.

We note that Lagrange does not speak of the "principle of least action" - a term associated with the name of Maupertuis and to troublesome polemics about prioritybut of a generic "general principle" that extends the theorem of Euler. These dialectical subtleties, of which there are other examples in his writings, generally indicate Lagrange's real opinions about men and facts, beyond conventional courtesies.

(A clarification: the modern texts sometimes create confusion in the nomenclature on variational principles. Physicists have decided to call "principle of least action" Hamilton's variational principle, which is a generalization of the principle of Maupertuis, Euler and Lagrange. It suffices, however, to consult a classic treatise of advanced mechanics [21] to restore clarity).

The results of the "Application" go far beyond all that which up to that time had been obtained by variational principles. Lagrange easily finds anew Euler's theorems on the unconstrained single point attracted by various centers of force, then generalizes them to the case of more points (free or constrained). Successively, he passes to continuous systems deriving for example the equations of motion of the vibrating string, of a free or constrained rigid body, and of compressible or incompressible fluid.

After having announced to the mathematical world the new discoveries, it would have been natural for Lagrange to have printed the complete treatise. Instead, the book was never published; like the memoir for the Berlin Academy, it disappeared without a trace. Lagrange doesn't say what happened in his letters, and we can only make hypotheses. The most reasonable is that Lagrange had decided that the principle of least action was not strong enough to support all of mechanics. Some indication of such a reconsideration is found in a memoir on the composition of forces written by Daviet de Foncenex, a student of Lagrange at the School of Artillery, and published in 1762 [10]. Foncenex writes that in mechanics "there exist no problems to which the method that is found at the beginning of the second part of the Traité de dynamique by $\mathrm{Mr}$ d'Alembert cannot be successfully applied". A few pages later, he states that the principle of virtual velocities.

can justly be considered the most fertile and most universal of mechanics: in effect, all of the others are easily reduced to it; the principle of live forces, and generally all those that the mathematicians have imagined to facilitate the solution of various problems are a purely mathematical consequence, or rather they are non other than this principle reduced to formulas.

It was precisely these two principles that Lagrange set as the foundation of the Méchanique analitique. It may be that he had expounded them in his course at the School of Artillery; certainly he discussed them with Foncenex. It may even be, according to his colleague and biographer Delambre, that Lagrange himself was the true author of the memoir. In any case, there is little doubt that Foncenex was expressing the thoughts of Lagrange [12, 14].

In 1766 Lagrange left Torino to succeed Euler as director of the Class of Mathematics of the Berlin Academy. He remained there for 21 years. It was an extremely productive period, during which his life and work were wholly one and the same.

In various memoirs of the Berlin period there appear topics and results that then reappeared in the Méchanique analitique. The principle of virtual work in conjunction 
with the principle of d'Alembert, as the basis for dynamics, appeared in 1765; the first general integrals of the equations of motion (by means of the systematic use of the potential of the forces) in 1779; the famous Lagrange equations of motion, in 1782. The use of arbitrary coordinates appeared implicitly already in the "Application" of 1762. Lagrange was gradually erecting the structure of his treatise.

The first explicit mention of the Méchanique analitique appeared in a letter to Laplace of 13 September 1782: "I have almost completed a treatise on analytical mechanics based solely on the principle or formula that I have set forth in the first section of the memoir attached here". In 1786 the work was finished. Lagrange wished to have it printed in Paris, where he hoped that the typographers would make fewer errors in composing the numerous formulas. A copy of the manuscript was carried to Paris by the Abbé Marie, an author of educational texts that Lagrange had known since the time of his first visit to Paris. Of the Parisian printers, only Desaint agreed to publish such an advanced text, and did so under the condition that Abbé Marie committed himself in writing to acquire the copies that remained unsold. The page proofs were corrected by Legendre, one of the other rising stars of French mathematics.

La Méchanique analitique was published in 1788, when its author was established in Paris. It was immediately clear to all experts that it was a masterpiece. But Lagrange, afflicted by a kind of depression and disgust for mathematics, was unable to enjoy his triumph. Delambre recounted that he didn't even open his copy.

\section{What does the Méchanique analitique contain?}

Every description of the Méchanique analitique cites the passage from the introduction stating that "no figures will be found in this work". To be precise, there are almost no figures found in any of the pages of Lagrange's Oeuvres. We have by now traveled quite a long way down the road to abstraction, but on this terrain Lagrange stands up to a comparison with the moderns. Even Euler, by that time elderly and almost blind, confessed that he was not able to completely understand some of the formulas used by Lagrange in a memoir on the motion of rigid bodies.

The use of analytical rather than geometrical methods pervades all of mathematical physics of the 1700s. But Lagrange goes beyond the simple choice of a language: the Méchanique analitique is an attempt to reduce mechanics to a branch of analysis. Lagrange based all of his own construction on a single formula that was supposed to constitute the most general relationship between forces, masses and motions in the presence of constraints and whose development, case by case, furnishes the differential equations for any problem whatsoever. According to Lagrange, higher mechanics was none other than the set of transformations of the fundamental formula by means of a formalized infinitesimal calculus, or rather, one reduced in its turn to a sort of super algebra.

This hyper-mathematical conception of mechanics has often been considered a characteristics of all of the mechanics of the eighteenth century. Nothing could be further from the truth: Newton, Euler and d'Alembert discussed in depth the nature of space and time, the principle of inertia, the concept of mass and the definition of force; Daniel Bernoulli performed many experiments in fluid dynamics and carefully considered the limits of the validity of his own theoretical model; Euler and Daniel Bernoulli were much concerned with technical physics. All told, the mathematicians of the 1700s addressed the reality of certain physical theories of our own day. Reading carefully between the lines we can see that Lagrange as well shows himself to have reflected on the physical foundations of mechanics. If in the Méchanique he limited himself to the formal aspect, it must also be because he presumed the reader to have knowledge of elementary mechanics. In the end, modern treatises of analytical mechanics proceed in exactly the same way.

As we have already said, the fundamental formula of Lagrange is the one that expresses the principle of virtual work, placed as the basis of the statics in the first part of the book. When d'Alembert's principle is added to that, dynamics is obtained, developed in the second part.

The principle of virtual work dates back to antiquity, and is based on the observation of the fact that in winches, levers and pulleys what is lost in distance is gained in force. For example, a man can lift an enormous weight thanks to a suitable system of pulleys, but he must pull the chain for a long time. Lagrange's formulation is more abstract. Using a modern terminology, he states that for a system of bodies connected by constraints without friction, the total work of the constraint forces is null for each displacement of the bodies compatible with the constraints. Let us in fact consider, for example, a system of points tied to each other by strings and forced to move along smooth surfaces. We effect a small trial (virtual) displacement of the points: we intuitively expect that the work of the constraints (also virtual) is always null. If then the system is in equilibrium, the active forces balance out the constrained forces; we thus deduce that, for small trial displacements about a configuration of equilibrium, the corresponding work of the active forces is also null. In formulas, the equilibrium is given by:

$P \delta p+Q \delta q+R \delta r+\cdots$ etc. $=0$,

where $P, Q, R, \ldots$ are the forces acting on the points of the system and $\delta p, \delta q, \delta r, \ldots$ are the projections of the virtual 
displacements along the directions of the forces. The remarkable aspect of this expression is that only the active forces appear, which are supposed to be known, and not the constraint forces, which are generally unknown [7].

In the first pages of the Méchanique Lagrange attempts a kind of proof of the principle of virtual work, based essentially on the hypothesis that the principle is intuitively valid for only two points. As ingenious as the reasoning is, it is difficult to believe that he considered it something more than a heuristic argument to show that the principle is sufficiently broad to cover elementary mechanics.

There exist several formulations of d'Alembert's principle, subtly different from one another. The one that follows is reasonably close to Lagrange's ideas (with a few simplifications and modernizations). We consider a system of points that are constrained and subject to forces. On the generic $i$ th point, of mass $m_{\mathrm{i}}$, acts force $\mathbf{f}_{\mathrm{i}}$. However, because of the restraints, the acceleration $\mathbf{a}_{\mathrm{i}}$ does not have the same direction as $\mathbf{f}_{\mathrm{i}}$. In effect, $\mathbf{f}_{\mathrm{i}}$ is able to accelerate the point only by means of one of its components equal to $m_{\mathrm{i}} \mathbf{a}_{\mathrm{i}}$, while the remaining component $\mathbf{f}_{\mathrm{i}}-m_{\mathrm{i}} \mathbf{a}_{\mathrm{i}}$ is eliminated by the restraints. If then the system were subject to the socalled lost forces $\mathbf{f}_{1}-m_{1} \mathbf{a}_{1}, \mathbf{f}_{2}-m_{2} \mathbf{a}_{2}, \ldots$, it would result in equilibrium.

We have thus led ourselves back to statics. If the constraints are without friction, the principle of virtual work can be applied to the lost forces. Decomposing each of such forces in parallel to the three axes of an orthogonal Cartesian system, we obtain the formula:

$\sum_{i}\left[\left(X_{i}-m_{i} \ddot{x}_{i}\right) \delta x_{i}+\left(Y_{i}-m_{i} \ddot{y}_{i}\right) \delta y_{i}+\left(Z_{i}-m_{i} \ddot{z}_{i}\right) \delta z_{i}\right]=0$,

where $\delta x_{1}, \delta y_{1}, \delta z_{1}, \ldots$ are the projections of the displacements along the three Cartesian axes.

Having established the general principle, Lagrange passes to the proof of the fundamental results of the mechanics of systems. In order he obtains Newton's second law for the free point, the conservation of the quantity of motion, the conservation of the moment of the quantity of motion, the conservation of energy, and the principle of least action. All of the principles of mechanics discovered since the times of Newton are logically ordered. We note that the conservation of the momentum is proved in the hypothesis that the system can be freely translated in a certain direction: that of the moment of momentum presuming that the system can freely rotate about a given axis. We have here a first vague nod to the idea that the symmetries of the system lead to laws of conservation, of which Noether's theorem, in 1918, will be the final expression.

Now we can better understand why in 1760 Lagrange had abandoned the principle of least action. In the Méchanique, the union of d'Alembert's principle and the formula of virtual work made it possible to prove both the principle of least action and the conservation of energy (in addition to all the principles of dynamics known up to that time). Instead, in the "Application", Lagrange had to impose the conservation of energy as an added condition to the principle of least action.

The Méchanique analitique is also remembered for the introductory chapters of a historical nature that open the principal sections of the text. Lagrange provides brief overviews of the history of the statics of the point, of the dynamics of the point, of hydrostatics and hydrodynamics, giving a survey of all the relevant works from Archimedes forward. Still today, in spite of the progress made in historical studies, these elegant summaries are pleasant and instructive. Their influence was notable: the survey by Ernst Mach, Die Mechanik in ihrer Entwickelung: historisch-kritisch dargestellt [22] owes much to Lagrange's notes on history. Naturally, this chapters must be read with a grain of salt; Lagrange expresses the opinions of his day (for a modern historian it would be unthinkable to write that during the Middle Ages and the Renaissance mechanics made no progress), and privileges citations to the works that came together in the Méchanique.

In addition to the mathematical style, there is the literary style. Like Archimedes, Galileo, Newton, Euler and d'Alembert, Lagrange too is an excellent writer. In his sentences we seem to hear an echo of the century of Louis $\mathrm{XIV}$. His style is concise, elegant, direct and extremely precise. The cadenced monotony of the style mirrors the uninterrupted flow of the formulas and theorems.

For those who have studied rational mechanics, a reading of the Méchanique analitique quickly transforms itself into a treasure hunt. The nonholonomic constraints appear on p. 214, the famous Lagrange equations are on p. 226, the ignorable coordinates on p. 237. We leave the rest of the hunt to the curious reader $[1,7,8,11,24,25$, 27].

\section{From the Méchanique analitique to the Mécanique analytique}

The history of the Méchanique analitique does not end with the publication of the first edition. All of the works on mechanics that Lagrange published after 1788 refer naturally to his treatise.

The course on analysis given by Lagrange at the École Polytechnique was the starting point for an innovative text entitled Théorie des fonctions analytiques [17]. The book is divided into three parts: the first regards the foundations of analysis, the second contains the applications to geometry. The third part-the most interesting for us-is a concise introduction to dynamics. 
This third part of the Théorie is on one level less advanced than the Méchanique analitique. It represents Lagrange's point of view of the foundations of dynamics and it is probable that it descends to a certain degree from the lessons of 1756 for the students in the School of Artillery in Turin. It begins with the kinematics of rectilinear motion; three-dimensional motion is simply the composition of three rectilinear motions along three axes that are mutually perpendicular; the principle of inertia is a fact of experience; the force acting on a body is measured by its acceleration; starting with $\mathrm{F}=m \mathrm{a}$, the laws of conservation for systems are obtained [23]. Those wishing to understand the logical structure of mechanics according to Lagrange should read the Théorie before the Méchanique.

At the beginning of the new century, Lagrange was by then over sixty, but he continued to produce works on mathematics and mechanics at an excellent level. In 1798 he published a physical proof of the principle of virtual work based on concepts of elementary mechanics. In competition with Laplace, he touched on various topics in celestial mechanics. In 1809 he expounded in two memoirs the method of variation of arbitrary constants, which from that time on has been one of the benchmarks of perturbation theory.

In the meantime, mechanics had gone forward in different directions. Fourier and Fossombroni had critically taken apart and then reconstructed the principle of virtual work; Poinsot had reformulated statics in the clear, classic language of synthetic geometry; Laplace had reorganized the principles of mechanics in the Traité de mécanique celeste [20]; Lazare Carnot and Prony had transformed the applied mechanics of the engineers into a genuine scientific discipline; Frisi, Euler, Prony and Poinsot had become aware that not only forces and velocity but also the moments of the forces and the angular velocities were composed according to the parallelogram law [4].

From his privileged point of observation in Paris, Lagrange followed these steps forward attentively. He was preparing a second edition of the treatise, in which he progressively added the recent results, almost as though wishing to show that his own formulation of mechanics was the definitive one. With these additions, the new text turned out to be around double of the original. The first volume of the second edition, now entitled Mécanique analytique (spelling had made progress as well) came out in 1811; the second, posthumous, in 1815 [18]. It was this edition that was read until about 1920 by those who aspired to carry out research in rational mechanics and which was reprinted at the end of the 1800 s in the Oeuvres ([19], vols. XI, XII).

Naturally, the growth of mechanics quite soon exceeded the limits of the second edition as well. Beginning in around 1820 there began to develop the new continuum mechanics of Cauchy, Poisson and Lamé for which the Lagrangian approach was inadequate. In the opposite direction, Hamilton and Jacobi pursued the way paved by Lagrange, creating modern analytical mechanics. By the time, in 1853, when a new edition with corrections and comments of Lagrange's second edition came out, the Mécanique analytique was a work that had been superseded in many aspects.

Historians have given differing opinions on the value and significance of the Méchanique. In the end this is the common destiny of all attempts at synthesis in the mathematical sciences: you could put together a fine anthology of diametrically opposed opinions, let's say, on Euclid's Elements or Bourbaki. Critics maintain that the Méchanique analitique is above all a re-ordering of previous results, that is aridly formal and that contains only a part of the splendid harvest of discoveries of the eighteenth century. Supporters of the Lagrangian approach instead note that the work contains much that is new (a theory of constraints, generalized coordinates, the various forms of the equations of motion, the theory of small oscillations in any system, and so forth), that the formal re-ordering of a set of theories is of no small account, and that the Méchanique analitique provides the first satisfying framework of the systems with an infinite number of degrees of freedom. Such discussions are restricted to a few specialists. The important fact is that today on the shelves in scientific libraries there are dozens of books entitled Analytical Mechanics. They display a wide range of styles and contents, but in each of them is easily recognizable the nucleus of theorems and concepts established by Lagrange more than two centuries ago.

(Translated from the Italian by Kim Williams).

\section{References}

1. Barroso Filho, W.: La mécanique de Lagrange: principes et méthodes. Karthala, Paris (1994)

2. Benvenuto, E.: La scienza delle costruzioni e il suo sviluppo storico, Florence, Sansoni (1981) (Rpt. Genoa, Edizioni di storia, scienza e tecnica, 2008)

3. Borgato, M.T and Pepe, L.: Lagrange a Torino (1750-1759) e le sue lezioni inedite nelle R. Scuole di Artiglieria, Bollettino di storia delle scienze matematiche 7: 3-43 (1987)

4. Caparrini, S.: The discovery of the vector representation of moments and angular velocity. Arch Hist Exact Sci 56, 151-181 (2002)

5. Caparrini, S.: An Unpublished Letter by Lagrange Concerning the Turin Academy of Science. Atti della Accademia delle Scienze di Torino 141, Classe di Scienze Fisiche, Matematiche e Naturali, pp. 45-52 (2007)

6. Caparrini, S., Fraser, C.: Mechanics in the Eighteenth Century. In: Buchwald, J., Fox, R. (eds.) The Oxford Handbook of the History of Physics, Oxford University Press, Oxford (in print) 
7. Capecchi, D.: History of virtual work laws: a history of mechanics prospective. Springer, Milan (2012)

8. Dugas, R.: Histoire de la mécanique, Neuchâtel, Griffon (1950). Eng. trans: A History of Mechanics, Neuchâtel, Griffon, 1955

9. Euler, L.: Methodus inveniendi lineas curvas maximi minimive proprietate gaudentes, sive solutio problematis isoperimetrici lattissimo sensu accepti. Busquet, Lausanne \& Geneva (1744), vol. 24, Rpt. Opera Omnia, S. 1

10. Foncenex, D.: de. Sur les principes fondamentaux de la mechanique. Miscellanea Taurinensia, II, 2, pp. 299-323 (1762)

11. Fraser, C.J.L.: Lagrange's early contributions to the principles and methods of mechanics. Arch Hist Exact Sci 28, 197-241 (1983)

12. Galletto, D.: La genesi della Mécanique analytique. In: La Mécanique analytique de Lagrange et son héritage: Torino, 26-28 ottobre 1989, 2 vols., supplement to the Atti dell'Accademia delle scienze di Torino 126, Classe di scienze fisiche, matematiche e naturali, vol. 2, pp. 277-370 (1992)

13. Guicciardini, N.: Reading the Principia: the debate on Newton's mathematical methods for natural philosophy from 1687 to 1736 . Cambridge University Press, Cambridge (1999)

14. Juskevic A.P., Taton R. (eds.) Correspondence de Leonhard Euler avec A. C. Clairaut, J. d'Alembert et J. L. Lagrange. In: L. Euleri opera omnia, s. IV A, vol. V, Basel, Birkhäuser (1980)

15. Lagrange, J.-L.: Application de la méthode exposée dans le Mémoire précédent à la solution de différents problèmes de dynamique. Miscellanea Taurinensia, II, 2, pp. 196-298 (1760). Rpt. [19, vol. I, pp. 365-468]

16. Lagrange, J.-L.: Méchanique analitique, Paris, Desaint (1788). (Rpt. Sceaux, Gabay (1989).

17. Lagrange, J.-L. Théorie des fonctions analytiques. Imprimerie de la Republique, Paris (1797)

18. Lagrange, J.-L. Mécanique analytique, 2 vols. Courcier, Paris (1811-1815). Rpt. (19, vols. XI, XII)

19. Lagrange, J.-L.: Oeuvres, 14 vols., Joseph Alfred Serret, (ed.) Paris, Gauthier-Villars (1867-1892)

20. Laplace, P.: S. de. Traité de mécanique celeste, 5 vols. Crapelet, Paris [an VII (1798)-1827]

21. Levi-Civita, T., Amaldi, U.: Lezioni di meccanica razionale. Bologna, Zanichelli (1991)
22. Mach, E.: Die Mechanik in ihrer Entwickelung: historisch-kritisch dargestellt, Leipzig, F. A. Brockhaus (1883). Eng. trans. The Science of Mechanics: A Critical and Historical Account of Its Development, T. J. McCormack, trans., La Salle, IL, Open Court (1989)

23. Maltese, G.La: Storia di $F=$ ma: la seconda legge del moto nel XVIII secolo. Florence, Olschki (1992)

24. Pulte, H.: Joseph Louis Lagrange, Méchanique analitique, first edition (1788). In: Grattan-Guinness, I. (ed.) Landmark writings in western mathematics: 1640-1940, pp. 208-224. Elsevier, Amsterdam (2005)

25. Sacchi Landriani, G., Giorgilli, A. (eds.) Sfogliando la Mechanique analitique: giornata di studio su Louis Lagrange: Milano, 19 ottobre 2006, Milan, LED (2008)

26. Speiser, D.: Discovering the principles of mechanics 1600-1800. In: Williams, K., Caparrini, S. (eds.) Birkhäuser, Basel (2008)

27. Szabò, I.: Geschichte der mechanischen Prinzipien und ihrer wichtigsten Anwendungen, Zimmerann, P., Fellmann, E.A. (eds.) 2nd edn. Birkhäuser, Basel (1987)

28. Truesdell, C.: Essays in the history of mechanics. Springer, Berlin (1968)

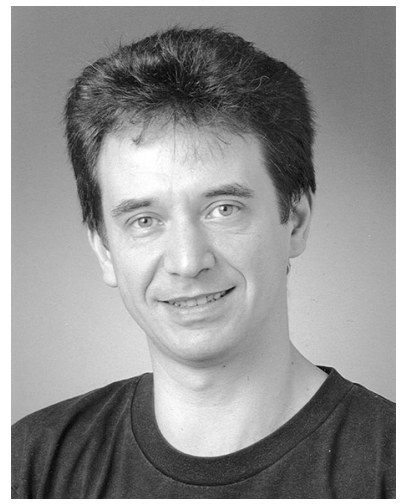

Sandro Caparrini holds degrees in Physics and in Mathematics and a Ph.D. in Mathematics from the University of Turin. His research interests are mainly focused on the history of the interaction between mathematics and mechanics from 1750 onward. He has held postdoctoral positions at the Dibner Institute (Harvard and MIT), at the Cohn Institute (Tel Aviv), at the Institute for the History and Philosophy of Science and Technology (Toronto) and at the Department of Mathematics of the University of Lille (France). In 2004 he was awarded the Slade Prize from the British Society for the History of Science. 